\title{
Sex and Gender Health Education Summit: Advancing Curricula Through a Multidisciplinary Lens
}

\author{
Alyson J. McGregor, MD, MA, FACEP, ${ }^{1}$ Eliza L. Chin, MD, MPH, FACP, FAMWA, ${ }^{2,3}$ Mary K. Rojek, PhD, MA, ${ }^{4}$ \\ Kathleen B. Digre, MD, ${ }^{5,6}$ Ana Maria Lopez, MD, MPH, FACP, ${ }^{6-8}$ Katharine Jenkins, ${ }^{9}$ \\ Leanne Johnston, BA, ${ }^{5,6}$ and Marjorie Jenkins, MD, MEdHP, FACP ${ }^{10}$
}

\begin{abstract}
Introduction: The Sex and Gender Health Education (SGHE) Summit was a national collaboration that engaged educational thought leaders from various health professions to advance curricula by integrating sex- and gender-based evidence into health education.

Materials and Methods: The SGHE Summit was held over a 2.5-day period April 2018 at the University of Utah. Pre- and postsummit surveys assessed attitudinal and knowledge changes.

Results: A total of 246 health care professionals and trainees from U.S. and International Institutions attended. One hundred fifty-seven presummit surveys and 115 postsummit surveys were completed. Postsummit beliefs: SGHE is critical to precision medicine (100\%); it is essential to include female animals in preclinical research studies (96\%); sex and gender concepts could be used to improve men's health (99\%). A teaching tool summarizes the initial questions to consider in SGHE.

Conclusion: The SGHE Summit was the first multiprofessional large-scale national effort focused on the integration of sex and gender knowledge into the education of all health professionals. Summit participants now represent a national network of educators and clinicians who recognize the centrality of sex and gender to health professionals' knowledge and practice. These educational efforts will ultimately ensure a more personalized health care delivery.
\end{abstract}

Keywords: health professions, sex and gender, education

\section{Introduction}

QEX- AND GENDER-BASED HEALTH is the science of the similarities and differences in health and illness between men and women. According to the National Institutes of Health, "Sex refers to biological differences between females and males, including chromosomes, sex organs, and endogenous hormonal profiles. Gender refers to socially constructed and enacted roles and behaviors which occur in a historical and cultural context and vary across societies and over time." 1 Sex and gender are inter-related variables that influence the etiology, risk factors, prevention, presentation, and response to treatment for all health conditions.
Sex and gender differences are increasingly recognized as a contributing factor to health disparities. Disparities can reflect differences in conditions that are specific to one sex or gender as well as those conditions that show differences in incidence, prevalence, morbidity, and mortality.

The evolution of sex- and gender-specific scientific knowledge and the establishment of an evidence base of differences have led us to understand that sex and gender have an impact on a patient's health. This understanding coupled with the lack of systemic integration into medical education ${ }^{2}$ became the motivation for the Sex and Gender Medical Education (SGME) Summit in 2015, which provided a venue for collaboration among nationally and internationally recognized

\footnotetext{
${ }^{1}$ Division of Sex and Gender in Emergency Medicine, Warren Alpert Medical School of Brown University, Providence, Rhode Island.

${ }^{2}$ American Medical Women's Association, Schaumburg, Illinois.

${ }^{3}$ University of California, San Francisco, San Francisco, California.

${ }^{4}$ Warren Alpert Medical School of Brown University, Providence, Rhode Island.

${ }^{5}$ Center of Excellence in Women's Health, University of Utah, Salt Lake City, Utah.

${ }^{6}$ University of Utah School of Medicine, Salt Lake City, Utah.

${ }^{7}$ Health Equity and Inclusion, University of Utah, Salt Lake City, Utah.

${ }^{8}$ Cancer Health Equity, Huntsman Cancer Institute, University of Utah, Salt Lake City, Utah.

${ }^{9}$ Sex and Gender Health Education Summit, Salt Lake City, Utah.

${ }^{10}$ Laura W. Bush Institute for Women's Health, Texas Tech University Health Sciences Center, Amarillo, Texas.
} 
experts in developing a roadmap for the incorporation of sexand gender-based concepts into medical education curricula, and highlighted the different methodologies and models for integrating Sex and Gender Based Medicine (SGBM) content into medical education. After the 2015 Summit, a toolkit and detailed summary proceedings were disseminated to all attendees, participating institutions, supporting organizations, national medical associations, and individuals.

After the success of the SGME Summit, the organizers agreed that future education was needed within all sectors of health care to help advance this knowledge and improve clinical practice. Interprofessional education (IPE) is becoming a more common component of medical school curricula in the United States. IPE programs are growing as they are increasingly viewed as a means of reducing medical errors and improving the health care system. ${ }^{3,4}$

The Sex and Gender Health Education (SGHE) Summit was designed to build upon the success of the SGME Summit while creating an interdisciplinary network and providing resources for health professionals to support and progress the integration of sex and gender differences into health professionals' education. To expand multidisciplinary opportunities in SGBH, health education leaders convened from five major professions-medicine, nursing, pharmacy, dentistry, and allied health at The University of Utah in April 2018. Invited attendees included health education faculty, student leaders, and professional and nonprofit organizational representatives who were interested in progressing sex and gender inclusion into health professionals' education and thus into future clinical care.

With an overarching goal to achieve lasting sex and gender integration into health professionals' education, the SGHE Summit goals were as follows: (1) navigate organizational and institutional curricular change, (2) create a stepwise plan for sex and gender integration, (3) receive valuable assessment guidance from national experts, (4) obtain access to resources on sex and gender curricular materials, (5) enhance IPE through a sex and gender approach, and (6) engage health professional faculty and stakeholders.

\section{Materials and Methods}

The SGHE Summit was a collaborative effort of the American Medical Women's Association, the Texas Tech University Health Sciences Center's Laura W. Bush Institute for Women's Health, the Mayo Clinic Rochester, and the University of Utah. Planning for the Summit included the formation of an executive planning committee, multiprofessional senior advisory and scientific program committees, a poster committee, local host committee and the establishment of a summit informational website (www.sghesummit2018.com) and the SGHE Summit Agenda (See Appendix).

Pre- and postassessment surveys of participants' knowledge, attitudes, and perceptions were obtained and are presented through descriptive analysis.

Two workshops were developed: Workshop A: Integrating Sex and Gender into an Interprofessional Curriculum and Workshop B: Leading and Sustaining Curricular Change. Workshop A gave Summit participants an opportunity to recognize how the integration of sex and gender into educational curricula could present in a classroom model. In Workshop B, participants discussed challenges in initiating and developing a successful program back at their own institutions. The workshops utilized small-group and roleplaying activities as evidence-based teaching delivery methods.

\section{Results}

\section{Attendees}

Two hundred forty-six health care professionals and trainees from 137 institutions and organizations across five health professions (medicine, nursing, pharmacy, allied health, and dentistry,) attended in person, with many others participating online. One seventy-five scholarship grant applications were awarded.

Summit attendees hailed from 36 different states in the United States and international regions as far as Canada, South Korea, and the Caribbean. In-person attendees included 205 women and 41 men. The attendees' specialty or degree designations were MD/DO 78, DDS/DMD 23, PharmD 27, Nursing 29, Allied health 8, Doctoral Degree (specialty not specified) 44, Other 37 (Table 1). Twenty-two attendees had a public health degree.

\section{Workshops $A$ and $B$}

Each workshop is further discussed in accompanying manuscripts; however, here we present brief descriptions of goals that were accomplished. Workshop A participants were able to (1) understand the breadth of evidence that adds to the understanding of sex- and gender-specific health in a variety of clinical scenarios, (2) utilize current active learning educational modalities to demonstrate inclusion of sex and gender into existing curricula, (3) create SMART objectives that demonstrate learning and assessment of sex and gender inclusive content, and (4) create a framework for initiating an integrative curricular change that is pertinent to specific professions. ${ }^{5}$

Workshop $\mathrm{B}^{6}$ participants created a framework to (1) understand the role of instructors, course/block directors, and curriculum committees in determining curricular content and change; (2) explain the impact of both internal and external factors to institutions (accreditation, clinical pressures) on shaping the curriculum; (3) convincingly articulate the importance of sex and gender knowledge for the maintenance of health and treatment of patients; and (4) develop confidence

Table 1. Sex and Gender Health Education Summit AtTendeEs by SPecialty/Degree

\begin{tabular}{lr}
\hline Specialty/degree & Total \\
\hline Medicine (MD/DO) & 78 \\
Dentistry (DDS/DMD) & 23 \\
Pharmacy (PharmD) & 27 \\
Nursing (various) & 29 \\
Allied health (various) & 8 \\
Doctoral degree (specialty not specified) & 44 \\
Other & 37 \\
Graduate degree & 18 \\
Undergraduate degree & 8 \\
Medical student & 9 \\
Undergraduate student & 2 \\
Total & 246
\end{tabular}


in the ability to persuade/negotiate a viewpoint around sex and gender curricular integration (ref SGHE Workshop B manuscript).

\section{Participants survey responses}

A survey was conducted at the beginning and end of the Summit using the Whova app. Summit survey respondent demographics are shown in Table 2, and survey results are shown in Tables 3 and 4 . There were 157 presummit survey respondents, which included 131 faculty, 6 residents, 8 students, and 12 other respondents. Among these, there were 133 women, 19 men, and 4 who responded as other gender. There were 115 postsummit survey respondents, which included 89 faculty, 5 residents, 5 students, and 16 others. Among these, there were 96 women and 19 men.

The summit was attended by individuals who were invested in promoting curricular excellence. Seventy-four percent of those completing the presummit survey had roles in curriculum development within their specialties. Eightyseven percent thought that they were familiar with sex and gender differences in health and disease. Yet, even among these individuals, new knowledge was gained and attitudes changed. By the end of the summit, there was almost universal agreement that SGHE could improve men's health (99\%) and was critical to precision medicine (100\%). Almost all also agreed that we needed to include female animals in preclinical research studies (96\%). The largest shift in attitude was in the belief that the FDA should consider recommending dosages based on the sex of the patient, which increased from $78 \%$ to $94 \%$. Almost all respondents indi-

Table 2. Sex and Gender Health Education Summit Survey Respondents' Demographics

\begin{tabular}{lc}
\hline Demographics $(\mathrm{N}=272)$ & Percentage (\%) \\
\hline Discipline & \\
Medicine & 46.8 \\
Dentistry & 12.3 \\
Pharmacy & 16.9 \\
Nursing & 11.7 \\
Allied health & 4.5 \\
Other & 7.8 \\
Position at institution & \\
Faculty & 83.4 \\
Staff & 3.2 \\
Student & 5.1 \\
Resident & 3.8 \\
Other & 4.5 \\
Preferred gender & \\
Woman & 84.7 \\
Man & 12.7 \\
Other & 2.5 \\
What best describes your institution? & \\
Large academic center & 74.2 \\
Private college/university & 23.8 \\
Private sector/professional organization & 2.0 \\
I have a role in curriculum development at my \\
institution/school \\
Yes \\
$\quad$ No
\end{tabular}

Presummit survey, $N=157$; postsummit survey, $N=115$. cated that they would consider integrating sex and gender concepts into all of their educational sessions (95\%). The overwhelming support for sex- and gender-based health among summit participants stands in contrast to the percentage of those indicating that sex and gender evidence was integrated across all 4 years of the curriculum at their institutions ( $14 \%$ presummit, $5 \%$ postsummit).

\section{Discussion}

\section{Awareness, action, and accountability}

The SGHE Summit was a historic undertaking as the first interprofessional conference to convene the five major health care professions-medicine, nursing, dentistry, pharmacy, and allied health-on the importance of SGHE. The full impact of the Summit will depend largely on the extent that the knowledge gained from the Summit can be implemented at educational institutions across the country, or what Dr. Lucinda Maine addressed in her capstone lecture as the Triple A: Awareness, Action, and Accountability.

The first task for those who attended the Summit was not only to increase their own awareness about the relevance of sex and gender for health education but also to increase awareness within their institutions. Simply asking the question, "Does sex and gender matter?" at every opportunity helps create the proper framework for understanding the issue. Being aware that educational resources are available for sharing among institutions can save valuable time and resources.

The next step is to turn awareness into action. This can be as simple as debriefing with colleagues, teaching one's mentors about the importance of sex and gender, using resources such as those available from the Laura W. Bush Institute for Women's Health at Texas Tech University Health Sciences, Canadian Institute of Gender and Health, or the National Institutes of Health Office of Research on Women's Health, encouraging others to use these materials and other available resources, and advocating for changes in curricular mapping software.

Attendees were encouraged to consider how sex and gender fit within their own organizations' visions and missions, and then to align SGHE efforts within that framework. For example, if the mission is to provide personalized care to patients, then providing care with a sex- and gender-focused lens becomes a critical component of fulfilling that mission because each patient has a sex and a gender. If the mission is to improve health outcomes, then considering the role of sex and gender is critical in understanding how health and illness are manifested in the community. For example, women are more likely to suffer injuries associated with sexual or intimate partner violence, while men are more likely to be victims of suicide or homicide. The same holds true for many diseases. For example, cardiovascular disease, a primary cause of mortality and morbidity in both men and women, is characterized by differences in pathophysiology, clinical presentation, and outcomes. $^{7}$ To improve outcomes, health systems will need to address differences in the prevention, diagnosis, and management of cardiovascular disease between men and women.

Turning awareness into action will require "measuring what matters." To determine if we have deficiencies in how we are teaching about sex and gender or in how we are providing clinical care, we need to measure what we are doing. The development of Multiprofessional Achievable Required Knowledge (MARK) goals for sex and gender 
Table 3. Sex and Gender Health Education Summit Pre- and Postsurvey Results

\begin{tabular}{|c|c|c|c|c|c|c|c|}
\hline \multirow{2}{*}{\multicolumn{2}{|c|}{ Question }} & \multicolumn{2}{|c|}{$\begin{array}{c}\text { Strongly/agree, } \mathrm{n} \\
(\%)\end{array}$} & \multicolumn{2}{|c|}{ Neither, n (\%) } & \multicolumn{2}{|c|}{$\begin{array}{l}\text { Strongly/disagree, } \\
\mathrm{n}(\%)\end{array}$} \\
\hline & & Pre & Post & Pre & Post & Pre & Post \\
\hline 1 & $\begin{array}{l}\text { I am familiar with the topic of sex and gender differences } \\
\text { in health and disease }\end{array}$ & $134(87)$ & $113(97)$ & $11(7)$ & $1(1)$ & $9(6)$ & $2(2)$ \\
\hline 2 & $\begin{array}{l}\text { Concepts of sex- and gender-based health can be used } \\
\text { to improve men's health }\end{array}$ & 149 (97) & $111(99)$ & $5(3)$ & $1(1)$ & 0 & 0 \\
\hline 3 & Sex and gender health is the same as women's health & $26(17)$ & $8(7)$ & $10(6)$ & $10(9)$ & $118(77)$ & $94(84)$ \\
\hline 4 & $\begin{array}{l}\text { The FDA should consider recommending dosages based } \\
\text { on the sex of the patient }\end{array}$ & $120(78)$ & $106(94)$ & $31(20)$ & $5(4)$ & $3(2)$ & $3(2)$ \\
\hline 5 & $\begin{array}{l}\text { Sex-and gender-based medicine is a fundamental aspect } \\
\text { of precision medicine }\end{array}$ & $146(95)$ & $111(100)$ & $7(4)$ & 0 & $1(1)$ & 0 \\
\hline 6 & $\begin{array}{l}\text { It is not necessary to include female animals in preclinical } \\
\text { research studies }\end{array}$ & $3(2)$ & $4(4)$ & $15(9)$ & 0 & 137 (89) & $107(96)$ \\
\hline 7 & $\begin{array}{l}\text { Sex- and gender-specific medicine focuses on the health } \\
\text { of the LGBT community }\end{array}$ & $66(43)$ & $50(45)$ & $40(26)$ & $26(23)$ & $48(31)$ & $36(32)$ \\
\hline 8 & $\begin{array}{l}\text { My institution has integrated sex and gender evidence } \\
\text { across the } 4 \text { years curriculum }\end{array}$ & $22(14)$ & $6(5)$ & $39(25)$ & $33(29)$ & $93(61)$ & $73(65)$ \\
\hline 9 & $\begin{array}{l}\text { My institution has developed objective structured clinical } \\
\text { examinations or other simulated patient cases, which } \\
\text { integrate sex- and gender-specific health }\end{array}$ & $34(22)$ & $21(19)$ & $42(27)$ & $30(27)$ & $78(51)$ & $61(54)$ \\
\hline & $\begin{array}{l}\text { I have included sex and gender evidence as part of my } \\
\text { courses and/or curriculum development }\end{array}$ & $102(66)$ & $71(64)$ & $28(18)$ & $18(16)$ & $25(16)$ & $22(20)$ \\
\hline
\end{tabular}

Total respondents: presurvey, $N=157$; postsurvey, $N=115$. Did not reply: presurvey, $N=3$ for all questions; postsurvey, questions 5,6 , $10, N=4$, all others $N=3$.

interprofessional health education will help create a competency-based approach to assessment. Multiple competencies can be associated with each entrustable professional activity (EPA) within the different health professions.

Measurement facilitates accountability, which can be demonstrated within different contexts. Sex and gender should be integrated into accreditation standards because these concepts are foundational in health and illness. Accountability should also be integrated into local and national examinations such as Objective Structured Clinical Examinations and board examinations, with examination questions being written by sex and gender experts. A sex- and gender-based framework should be integrated into curricular maps and surveys such as course evaluations and graduating student surveys. At the federal level, for example, the FDA

\section{Table 4. Sex and Gender Health Education Summit Postsurvey Results}

Has this conference changed your opinion of the importance of sex- and gender-specific health?

$\begin{array}{ll}\text { Yes } & 88(81 \%) \\ \text { No } & 21(19 \%)\end{array}$

How likely are you to consider integrating sex and gender concepts in all of your educational sessions?

Very likely

$80(73 \%)$

Likely

Neither likely nor unlikely

$24(22 \%)$

$4(4 \%)$

$1(1 \%)$

Would you like us to use the Whova App at future educational events?
Yes
$105(96 \%)$
No
$4(4 \%)$

Total respondents, $N=115$. Did not reply: six respondents for each question. and NIH, this framework should be factored into data, compliance, and funding.

Dr. Maine concluded that ultimately, faculty are accountable to their students and their patients. This necessitates the inclusion of sex and gender into health professions education, so that students learn how to provide appropriate and personalized care to each and every patient.

\section{Recurring themes and keys to curricular change}

Several recurring themes emerged over the course of the Summit, which serve as keys to curricular change.

Relevance of sex and gender. The first step associated with integrating sex and gender content into curricula is recognizing the relevance of sex and gender to research, education, and practice. As Dr. Marjorie Jenkins emphasized at the outset of the Summit, "Every patient has a sex and a gender." This perspective should be the lens with which we approach each patient. Both biology (sex) and gender (roles, identities, expectations, and behaviors) affect health and illness, and are manifested in every single patient. Sex and gender are foundational variables in health care, and are integral to the delivery of personalized care.

The LGBTQ+ community's needs are included, but they are a subset of sex and gender health. The field of sex and gender health includes lesbian, gay, bisexual, transgender, queer (LGBTQ+) individuals, but it is not synonymous with the care of this special population because sex and gender health apply to all patients. Members of the LGBTQ+ community have unique health care needs that need to be recognized and addressed. Members of these groups often have difficulty receiving care because they fear discriminatory or dehumanizing treatment by health care providers. 
Suggestions offered to health care providers included asking such patients how they wished to be addressed and treating the anatomy that was presented.

Sex and gender intersect with public health. Sex and gender considerations are integral to public health in many ways, including access, treatment needs and interventions, epidemiology, and medical errors. Consider the example of substance abuse. Historically, alcohol abuse was more common in men, but women are catching up. This leads to sex-specific consequences such as increased breast cancer risk or testicular atrophy or breast enlargement. Alcohol and drug use are addictive and coping behaviors, and they increase the risk of intimate partner violence. In addiction treatment, sex hormones influence reward pathways. For many if not most diseases, the intersection of sex and gender can have epigenetic effects, which are observed on the population level. Ignoring sex and gender can contribute to medical errors, which are currently the third leading cause of death in the United States. The primary factor in medical errors is adverse drug events, which are more common among women. Sex and gender considerations are relevant for public health interventions and policies.

Interprofessional collaboration is key. Interprofessional discussions during workshops and small-group activities fostered a greater understanding of the relevance of sex and gender across multiple knowledge domains and practice areas. Participants shared insights from their own disciplines about the importance of sex and gender concepts in basic science, social science, clinical care, or curriculum development. The small-group experiences demonstrated the effectiveness of an interprofessional model that could be applied locally within institutions to engage both faculty and students.

Work within existing frameworks. There is no doubt that implementing broad curriculum change can be challenging, but integrating sex and gender into existing curricula does not have to be difficult. These concepts can be woven into existing competency frameworks, particularly if an educational need or a knowledge gap has already been identified. Course materials can be examined for sex and gender bias. The first step may be as simple as either adding a few extra lecture slides or changing the sex of case patients and examining how that impacts interpretation of the case, especially diagnostic and treatment decisions.

Use available resources. Many resources are available to facilitate curricular integration, so that reinventing the wheel is not necessary. Open-source training modules, case materials, and other curricular materials are available through the Laura W. Bush Institute for Women's Health and the Sex and Gender Health Collaborative (a program of the American Medical Women's Association). Extensive resources for researchers and faculty are available through the Canadian Institutes of Health and the National Institutes of Health Office of Research on Women's Health. A comprehensive list of sex and gender resources can be found in the proceedings from the 2015 SGME Summit (www.sgbmeducationsummit.com) as well as from the Sex and Gender Health Collaborative (www .amwa-doc/sghc). The 2015 Summit proceedings ${ }^{8}$ also provide a roadmap for individuals and institutions that are considering more substantive curricular change.

Align with professional competencies and EPAs. Summit participants were exhorted to work toward change within their own health professions. Understanding the competencies and EPAs that guide curriculum development will be critical to change. Although there is some variation in competencies and EPAs across professions, there are also many common themes. Aligning curricular goals to competencies and EPAs within one health profession can serve as a model for change within other health professions.

Students are allies in SGHE. Students have been allies and effective grass roots advocates in highlighting the importance of sex and gender within their institutions. Students have asked questions, asked for curriculum reform, and

Table 5. Sex and Gender Health Education Teaching Tool: SeX and Gender Bias Questions Across Domains

Basic science Were laboratory animals both male and female?

Pharmacology Were both men and women included in clinical trials? Were data analyzed based on sex differences? Are there pharmacokinetics and pharmacodynamics differences for a specific treatment between men and women?

Anatomy and physiology Pathophysiology Epidemiology

Diagnostic tests Public health Rehabilitation Social factors

Patients

Health care providers
Are there functional differences in size and functioning of bodies, organs, or vessels that matter?

Does disease presentation, management, and outcome differ between men and women?

Are there differences in prevalence? Are prevalence rates being measured correctly, or is misdiagnosis leading to bias?

Is a test equally valid in men and women?

Are there differences in access based on sex, gender, or other factors?

Do patients need different therapies, or do they recover differently based on sex and gender?

Which gendered aspects of a patient's life result in illness or affect a patient's ability to care for themselves?

How do patient biases lead them to avoid seeking care or to misinterpret their symptoms? How are sex and gender inter-related in problems of addiction, victimization, and violence?

How would you interpret this case differently if the patient was the opposite sex? How do provider biases lead to misinterpretation of patient symptoms? How does bias lead to misdiagnoses and unnecessary hospitalizations? How does ignoring sex and gender contribute to medical errors or iatrogenesis? 
participated in curriculum audits of sex and gender content. Students have also successfully advocated for sex and gender to be recognized as an essential knowledge domain at the Michigan State Medical Society.

\section{A teaching tool to illuminate gender bias across domains}

Over the past three decades, a great deal of research has documented differences between women and men across many domains, but these differences are not well understood by many clinicians or educators. Misunderstanding can lead to unintentional bias that translates into suboptimal patient care and medical errors. Although some bias is conscious, the majority of bias is unconscious. Asking appropriate questions can help elucidate potential bias. Examples of initial questions to consider that will illuminate potential gender bias can be found in Table 5. These questions can serve as a teaching tool for faculty and students. They can easily be used with case presentations, in journal clubs, and with many other teaching methods. These questions are the underlying questions that Summit presenters and participants have asked to be better scientists, clinicians, and educators.

Asking questions about bias will improve not only clinical care, but it will also affect how we address health problems on a societal level through public health initiatives. The task for health profession educators is to uncover these biases for themselves and for their students. Providing faculty development about integrating sex and gender into curricula will be essential for success.

\section{Conclusion}

The SGHE was a national collaboration dedicated to engaging educational thought leaders from various health professions to create a roadmap for integrating sex- and gender-based evidence into health education. This was the first large-scale national effort directed toward the integration of sex and gender knowledge into the education of all health professionals.

Summit participants now form a national network of educators and clinicians who recognize the centrality of sex and gender to health professionals' knowledge and practice. They have the tools to begin creating networks within their home institutions. Some participants have already begun collaborating to share knowledge and resources. Follow-up surveys will assess the impact of the Summit at both the local and the national levels. As new resources become available, that information will be shared with Summit attendees. A future Summit (planned for 2020) will provide opportunities to engage even more curriculum leaders within the health care landscape.

These educational efforts to integrate sex and gender into multiple health professions curricula will ultimately ensure more personalized health care delivery.

\section{Acknowledgments}

Special thanks to the SGHE Summit Administrative team including Katherine Jenkins, Summit Logistics lead; Leanne Johnston, Administrative Program Coordinator, Center of Excellence in Women's Health Utah, BIRCWH and WRHR
Programs; Laura Gardner, Summit Social Media Lead, MD Candidate 2019, University of Utah School of Medicine. Additional gratitude to SGHE Summit Outreach Team that includes Kristine Lalic, coordinator, Adina Greene, Lori Horhor, Sally Kim, and Tannaz Safari.

\section{Author Disclosure Statement}

No competing financial interests exist.

\section{Funding Information}

Funding for the Summit was provided by the American Medical Women's Association (AMWA), the Laura W. Bush Institute for Women's Health (LWBIWH), the Mayo Clinic, the University of Utah Health as well as Texas Tech University Health Sciences Center School of Medicine, University of Utah School of Dentistry, National Association of Nurse Practitioners in Women's Health, Brown University Division of Sex and Gender in Emergency Medicine, Florida State University College of Medicine, and consumer education and advocacy organization, HealthyWomen.

\section{References}

1. National Institutes of Health. Office of Research on Women's Health. Sex and Gender. Available at: https://orwh.od .nih.gov/sex-gender Accessed May 2, 2018.

2. Jenkins MR, Hermann A, Tashjian A, et al. Sex and gender in medical education: A national student survey. Biol Sex Diff 2016;7(Suppl 1):45.

3. Roethel K "Medical Schools Push Teamwork". US News \& World Report. 2012. Available at: https://www.usnews.com/ education/best-graduate-schools/top-medical-schools/articles/ 2012/03/19/medical-schools-push-teamwork Accessed April $5,2012$.

4. Coalition for Patients' Rights. "Coalition members discuss value of collaboration in diabetes patient care". 2012. Available at: https://www.news-medical.net/news/20120409/ Coalition-members-discuss-value-of-collaboration-in-diabetespatient-care.aspx Accessed April 9, 2012.

5. Safdar B, Jarman AF, Barron R, et al. Integrating Sex and Gender into an Interprofessional Curriculum: Workshop Proceedings from the 2018 Sex and Gender Health Education Summit. J Womens Health 2019;28:1737-1742.

6. Templeton K, Halpern L, Jumper C, Carroll RG. Leading and Sustaining Curricular Change: Workshop Proceedings from the 2018 Sex and Gender Health Education Summit. J Womens Health 2019;28:1743-1747.

7. Shaw LJ, Bugiardini R, Merz CN. Women and ischemic heart disease: Evolving knowledge. J Am Coll Cardiol 2009; 54:1561-1575.

8. Chin EL, Hoggatt M, McGregor AJ, et al. Sex and gender medical education summit: A roadmap for curricular innovation. Biol Sex Diff 2016;7(Suppl 1):52.

Address correspondence to: Alyson J. McGregor, MD, MA, FACEP Division of Sex and Gender in Emergency Medicine Warren Alpert Medical School of Brown University 55 Claverick Street Providence, RI 02903

E-mail: alyson_mcgregor@brown.edu 


\section{Appendix A1. Sex and Gender Health Education Summit Agenda}

Sunday April 8, 2018

4:30 pm Poster Session and Opening Reception

Janice Werbinski, MD, FACOG, NCMP

Clinical Associate Professor Emerita

Homer Stryker School of Medicine, Western Michigan University

Executive Director, Sex and Gender Health Collaborative

6:00 pm Welcome

Susan Sheehan

President and Chief Operating Officer, Huntsman Cancer Foundation

Connie Tyne, MS

Executive Director, Laura W. Bush Institute for Women's Health

6:15 pm Oral Poster Presentations

Moderator:

Tracy Madsen, MD, ScM, FACEP

Assistant Professor of Emergency Medicine

Division of Sex and Gender, Warren Alpert Medical School, Brown University

6:45 pm Keynote:

Sex and Gender in Health Education: Students Expect It, Patients Deserve It

Cara Tannenbaum, MD

Scientific Director, Institute of Gender and Health of the Canadian Institutes of Health Research Professor, Faculties of Medicine and Pharmacy, Université de Montréal, Canada

\section{Monday, April 9, 2018}

8:00 am Welcome

Wyatt R. Hume, DDS, PhD

Dean, University of Utah, School of Dentistry

8:10 am Sex and Gender: Building Blocks Universal Terminology

Tracy Madsen, MD, ScM, FACEP

Assistant Professor of Emergency Medicine

Division of Sex and Gender, Warren Alpert

Medical School, Brown University

8:25 am Looking Forward: Framework for This Summit

Alyson J. McGregor, MD, MA, FACEP

Director, Division of Sex and Gender in Emergency Medicine

Director, SGEM Fellowship; Associate Professor, Emergency Medicine

Warren Alpert Medical School, Brown University

8:40 am Advancing Sex and Gender Education Through Interprofessional Education (IPE)

Moderator:
Leslie Halpern, DDS, MD, PhD, MPH, FACS

Professor, Section Head, Oral and Maxillofacial

Surgery

University of Utah School of Dentistry

Panelists:

Sara Gordon, DDS, MS

Professor of Oral Medicine, Associate Dean for Academic Affairs

University of Washington School of Dentistry

John Luk, MD

Assistant Dean for Interprofessional Integration

Dell Medical School, University of Texas at Austin

Rebecca Sleeper, PharmD, FCCP, FASCP, BCPS

Associate Dean of Curriculum, Professor of Pharmacy Practice, Geriatrics

School of Pharmacy, Texas Tech Health Sciences Center

Lorie Richards, PhD, OTR/L, FAHA

Chair, Occupational and Recreational Therapies Department

Editor-in-Chief, American Journal of Occupational Therapy

Health Sciences Center, University of Utah

10:15 am Hitting the MARK in Sex and Gender:

Developing Multi-Professional Achievable Required Knowledge

Moderator:

Timothy W. Farrell, MD, AGSF

Associate Professor of Medicine (Division of Geriatrics)

Physician Investigator, VA SLC Geriatric Research, Education, and Clinical Center

Director, University of Utah Health Interprofessional Education Program University of Utah School of Medicine

Panelists:

Susan Cox, MD, MA

Executive Vice Dean for Academics; Chair, Department of Medical Education

President Elect, Alliance for Clinical Education

Dell Medical School, The University of Texas at Austin

Laurie M. Lauzon Clabo, PhD, RN

Dean and Professor

Wayne State University College of Nursing

Amy Pittenger, PharmD, MS, PhD

Associate Professor, Department of Pharmaceutical Care \& Health Systems

Director, Interprofessional Education and Pharmacy Learning Collaborative

University of Minnesota College of Pharmacy 
Lea Erickson, DDS, MSPH

Associate Dean for Education and Student Life Professor, University of Utah School of Dentistry

12:00 pm Welcome from Sponsors

Eliza Lo Chin, MD, MPH, FACP

Executive Director, American Medical Women's Association

Assistant Clinical Professor of Medicine, University of California San Francisco

Virginia Miller, PhD

Professor of Surgery and Physiology

Director, Women's Health Research Center, Mayo Clinic

12:10 pm Lunch Presentation

Sex and Gender: What Do Students Think?

Moderator:

Kim Templeton, MD, FAMWA

Professor of Orthopedic Surgery

Director, Orthopedic Residency Program, University of Kansas Medical Center

Past President, American Medical Women's Association

Panelists:

Anne Drolet, MS

Student President, American Medical Women's Association

MD Candidate, College of Human Medicine, Michigan State University

Alyssa Herrmann, MD

Member, American Medical Women's Association, Women's Health Working Group

Resident in Obstetrics and Gynecology, Cleveland Clinic

Daniel Gouger, MD

Post-Doctoral Fellow, American Medical Student Association

1:15 pm Workshop A: Integrating and Assessing Sex and Gender in Curricula

Alyson J. McGregor, MD, MA, FACEP

Director, Division of Sex and Gender in Emergency Medicine

Director, SGEM Fellowship

Associate Professor, Emergency Medicine

Warren Alpert Medical School, Brown University

Basmah Safdar, MD, MSc, FACEP

Director, Chest Pain Center

Associate Professor, Yale School of Medicine

Daniel Gouger, MD

Post-Doctoral Fellow

American Medical Student Association

Rebecca Barron, MD, MPH

Assistant Professor, Emergency Medicine

Warren Alpert Medical School, Brown University

Angela Jarman, MD

Clinical Instructor; Fellow, Division of Sex and

Gender in Emergency Medicine
Warren Alpert Medical School, Brown University

Tess Wiskel, MD

Resident in Emergency Medicine

Warren Alpert School of Medicine, Brown University

3:00 pm Curricular Integration Tips: Making Workshop A Work for You

Jorie Colbert-Getz, PhD, MS

Assistant Dean of Assessment and Evaluation

Faculty Appointment, Department of Internal Medicine

University of Utah School of Medicine

Monday Recap and Tuesday Plans

Marjorie Jenkins, MD, MEHP, FACP

Professor of Medicine; Associate Dean for Women in Science

Chief Scientific Officer, Laura W. Bush Institute for Women's Health

Texas Tech University Health Sciences Center

6:00 pm Dinner Program: A Trans Healthcare Panel

Moderator:

Kathryn Bond Stockton, PhD

Dean of the School for Cultural and Social Transformation

Associate Vice President for Equity and Diversity Distinguished Professor of English, University of Utah

Panelists:

Gabriella Blanchard, BSW

Interim Director, Coordinator of Education and Outreach, LGBT Resource Center, University of Utah

Nicole L. Mihalopoulos, MD, MPH

Associate Professor, Pediatrics; Chief, Division of Adolescent Medicine

University of Utah School of Medicine

Tara Sharifan, PsyD

Wasatch Front Wellness, Salt Lake City, Utah

Hollie Hancock, EdD, LCMHC

Iron Mountain Counseling, Salt Lake City, Utah

Rixt Anna Catharina Luikenaar, MD, FACOG

Transgender Health / Obstetrics and Gynecology, University of Utah

Tuesday, April 10, 2018

7:00 am Breakfast with the Experts

Lauren Walter, MD, FACEP

Faculty Branch President and Region 5 Governor American Medical Women's Association Associate Professor, Emergency Medicine University of Alabama at Birmingham School of Medicine

7:55 am Welcome

A. Lorris Betz, MD, PhD

Senior Vice President, University Health Sciences Interim Executive Dean, University of Utah School of Medicine 
8:00 am Workshop B: Leading and Sustaining Curricular Change

Marjorie Jenkins, MD, MEHP, FACP

Professor of Medicine; Associate Dean for Women in Science

Chief Scientific Officer, Laura W. Bush Institute for Women's Health

Texas Tech University Health Sciences Center

Rob Carroll, PhD

Associate Dean for Medical Education

Professor, Physiology, Brody School of Medicine, East Carolina University

Kim Templeton, MD,

Professor of Orthopedic Surgery; Director, Orthopedic Residency Program

University of Kansas Medical Center

Past President, American Medical Women's Association

Cynthia Jumper, MD, MPH

Professor of Medicine, Vice President of Health Policy

Co-Director, Sex and Gender Health Education

Curriculum

Laura W Bush Institute for Women's Health

Texas Tech University Health Sciences Center

Michael Gonyeau, BS Pharm, PharmD, MEd, FNAP, FCCP, BCPS, RPh

Clinical Professor and Interim Chair

Department of Pharmacy and Health Systems

Sciences

Director of Undergraduate and Professional Programs

Northeastern University School of Pharmacy

Leslie Halpern, DDS, MD, PhD, MPH, FACS

Professor, Section Head, Oral and Maxillofacial Surgery

University of Utah School of Dentistry
10:00 am Intersection of Sex and Gender and Public Health

Esther Choo, MD, MPH

Associate Professor

Center for Policy and Research in the Department of Emergency Medicine

Oregon Health and Science University

Ana Maria Lopez, MD, MPH, FACP

Associate Vice President Health Equity and Inclusion

University of Utah Health Sciences

Director, Cancer Health Equity, Huntsman Cancer Institute

Professor of Medicine, University of Utah School of Medicine

Sue Kendig, JD, WHNP-BC, FAANP

Women's Health Integration Specialist

Policy Director, National Association of Nurse Practitioners in Women's Health

SSM Health, St. Mary's Hospital in St. Louis, Missouri

11:00 am Capstone Lecture

Achieving Sex and Gender IPE Requires Triple A: Awareness, Action, and Accountability

Lucinda Maine, $\mathrm{PhD}, \mathrm{RPh}$

CEO and Executive Vice President American Association of Colleges of Pharmacy

Wrap Up and Adjourn

Marjorie Jenkins, MD, MEHP, FACP

Professor of Medicine, Associate Dean for Women in Science

Chief Scientific Officer, Laura W. Bush Institute for Women's Health

Texas Tech University Health Sciences Center

11:45 am Lunch and Networking 